OPEN ACCESS

Edited by:

Horst Treiblmaier,

MODUL University Vienna, Austria

Reviewed by:

Remo Pareschi,

University of Molise, Italy

Chen Feng

University of British Columbia

Okanagan, Canada

*Correspondence:

Sinclair Davidson

sinclair.davidson@rmit.edu.au

Specialty section:

This article was submitted to

Non-Financial Blockchain,

a section of the journal

Frontiers in Blockchain

Received: 18 September 2019 Accepted: 20 November 2019

Published: 04 December 2019

Citation:

Berg C, Davidson S and Potts J

(2019) Blockchain Technology as

Economic Infrastructure: Revisiting the

Electronic Markets Hypothesis.

Front. Blockchain 2:22.

doi: 10.3389/fbloc.2019.00022

\section{Blockchain Technology as Economic Infrastructure: Revisiting the Electronic Markets Hypothesis}

\author{
Chris Berg, Sinclair Davidson* and Jason Potts \\ RMIT Blockchain Innovation Hub, RMIT University, Melbourne, VIC, Australia
}

In the late 1980s and early 1990s, the electronic markets hypothesis offered a prediction about effect of information technology on industrial organization, and many business writers forecast significant changes to the shape and nature of the firm. However, these changes did not come to pass. This paper provides an economic analysis of why, using the transaction cost economic framework of Ronald Coase and Oliver Williamson. Non-hierarchical corporate organization struggled against contracting problems in the presence of possible opportunistic behavior. Technologies of trust offer an institutional mechanism that acts on the margin of trust, suppressing opportunism. The paper concludes that blockchain technology provides an economic infrastructure for the coordination of economic activity and the possible realization of the electronic markets hypothesis.

... the arrival of any new infrastructural technology opens the future to speculation. It creates an intellectual clearing in which the imagination is free to play, unconstrained by old rules and experiences. (Carr, 2004).

Keywords: electronic markets hypothesis, transaction cost economics, blockchain technology, industrial organization, the theory of the firm

\section{INTRODUCTION}

Technologists and futurists offer us a vision of fundamental economic changes as a result of recent advances in digital technology. For example, we read that artificial intelligence presents a deep and transformative challenge to employment and work practices (Chace, 2016; Daugherty and Wilson, 2018; Morris, 2019), or even a challenge to the market economy and capitalism itself (Mason, 2015; Bastani, 2018). But previous generations had their own ideas about how of the technology could restructure the institutions of the market economy. In the 1980s and 1990s, a generation of management scholars declared that the rise of distributed networked organizations connected by communications technologies would transform the hierarchical corporate form (Miles and Snow, 1984, 1986; Bleecker, 1994; Harris, 2002). For Byrne (1993), the future of corporate capitalism was characterized a "network of independent companies, suppliers, customers, even erstwhile rivalslinked by information technology to share skills, costs, and access to one another's markets. It will have neither central office nor organization chart. It will have no hierarchy, no vertical integration."

This prediction was a speculative mainstay of the business press. In a series of papers with various co-authors, Thomas Malone formulated a clear hypothesis as to the impact of information 
technology on industrial organization in the late 1980s and early 1990s (Malone, 1987; Malone et al., 1987, 1989; Malone and Rockart, 1991). Malone's "electronic markets hypothesis" offered an economic model of changes in industrial organization grounded in the economics of transaction costs. The predicted change to corporate organization did not come to pass. Attempts to develop networked or virtual organizations have faced problems around coordination and trust (Handy, 1995; Jones and Bowie, 1998; Hughes et al., 2001; Kasper-Fuehrera and Ashkanasy, 2001; Shockley-Zalabak et al., 2001; Crossman and Lee-Kelley, 2004; Rasmussen and Wangel, 2007; Riemer and Klein, 2008).

In this paper, we re-examine the electronic markets hypothesis in the light of blockchain technology - a technology which economizes on trust (Berg et al., 2017, 2019; Davidson et al., 2018; Werbach, 2018). By situating the electronic markets hypothesis clearly in a transaction cost framework developed by Williamson (1985), we can identify the margins at which trust shapes industrial organization. The paper argues that blockchain technology provides an infrastructure which allows for the coordination of economic activity, and hence the realization of the possibilities of the electronic markets hypothesis.

The paper proceeds as follows. Section 2 looks at the electronic markets hypothesis as formulated by Malone and co-authors and situates it within the transaction cost school of economics. In section 3 , the paper considers the role that trust plays in economic coordination and the relationship between opportunistic behavior and trust in the Williamsonian framework. Section 4 details how blockchains act on trust. Section 5 concludes.

\section{THE ELECTRONIC MARKETS HYPOTHESIS}

From an economic perspective the electronic markets hypothesis builds on work undertaken by economics laureates Ronald Coase and Oliver Williamson. Coase (1937) asked the question why we observe firms within a free market economy. After all, one of the theoretical benefits of a free market economy is that it is "self-regulating" yet within an actual economy we observe many instances where economy activity is not self-regulating but is rather directed by management. Coase's solution to this paradox was to point out that there were costs to using the price system and that over some ranges of economic activity those costs were higher in the market than they were in a firm. Consequently, we would expect to observe some economic activity taking place within firms and other economic activity taking place within markets. The identification of these transaction costs would later earn Coase the economics Nobel in 1990.

Coase, however, did not operationalize his insights and it fell to the 2009 Nobel laureate Oliver Williamson to expand on Coase's work. Williamson's best known work is his 1985 book The economic institutions of capitalism. He operationalizes Coase's insight by imagining a make-or-buy decision. A firm may either acquire a component for its own manufacturing process by buying that component on the market, or by making that component in-house. Williamson carefully describes the circumstances that would lead to either a make or a buy decision. What is important for our immediate purposes is that (private) economic activity takes place either within hierarchy (firms) or within firms. The determinants of where that economic activity takes place are largely transaction costs.

Malone et al. (1987) make the argument that information technology (computers) have dramatically reduced the cost of processing and communication information. While this may seem trivially true they identify three effects this may have on industrial organization. First, an "electronic communication effect." This is an increase in the efficiency of communication that can positively impact both hierarchy and markets. Then a "electronic brokerage effect." This allows buyers and sellers to interact directly with each other. In modern language this corresponds to networked markets and platforms. Finally they point to an "electronic integration effect." Here information technology does not just change the speed of communication but changes the processes that capture and deploy information. As Malone, Yates, and Benjamin describe it, it is this effect that largely drives their electronic markets hypothesis: “... the overall effect of this technology will be to increase the proportion of economic activity coordinated by markets." In this story, information technology economizes on communication costs, lowers transaction costs overall, and leads to more market activity relative to hierarchy. We argue below that Malone, Yates, and Benjamin were correct, but for the wrong reason.

In an interview to mark the twentieth anniversary of the electronic markets hypothesis it was put to Malone that Amazon, eBay, and Google represented predictive successes of the hypothesis (Wigand, 2011). This notion may strike some readers as being counter-intuitive-after all these three organizations could also be described as large hierarchical firms. That is one interpretation-Amazon and Alphabet (Google's parent company) could also be described as venture capital incubators that provide an internal capital market financing to high-risk technology start-ups. That is an argument we do not pursue here. Rather we want to point out that these firms are consistent with the electronic brokerage effect that Malone, Yates, and Benjamin predicted in 1987. What we can observe now is that there is greater usage of market forces within hierarchical structures. That is not quite what the electronic market hypothesis predicted.

\section{TRUST AS A COORDINATING FACTOR}

Mainstream neo-classical economic theory suggests that the economic problem is a logical problem: how to best make use of the resources available to society. In a world of scarcity and limited resources, this involves making choices. In that theory the price mechanism operates as a rationing device to allocate resources. We have already discussed the Coasean view that resource allocation also occurs within firms and not just as a result of market pricing. There is, however, a more fundamental critique of the mainstream view.

F. A. Hayek-the 1974 economics laureate-argued in 1945 that the economic problem was not merely a logical mapping 
of resources to various usages given known prices (Hayek, 1945). The economic problem that any society faced was that of dispersed information. As a result it was unclear what resources society had available to it, what alternative uses of those resources could be, and prices had to be discovered in the market, they were not simply given. This insight was important within the context of a debate that raged in the 1930s between Ludwig von Mises, F.A. Hayek, and socialist economists, notably Oskar Lange (see Lavoie, 1985a,b). Mises had argued that in the absence of market pricing that opportunity costs could not be established and subsequently resource allocation would be inefficient (i.e., consumer demand could not be met). Lange had responded that market prices could be simulated either through an accounting process or estimated using (in those days rudimentary) econometric techniques. Hayek's contribution to the debate was that of dispersed information-no central planner could ever have enough information to make the necessary calculations that Lange envisaged. Mises had also argued that even if central planners (bureaucrats) did have the necessary information they did not have the same incentives as entrepreneurs did to make sound economic (i.e., profitable) decisions. Time has resolved the socialist calculation debatenonetheless the arguments that both Hayek and Mises made remain important. Dispersed information remains a problem and the incentives decision makers face remain important.

In a 2003, book chapter Malone (2003) revisited the electronic markets hypothesis. Here, Malone restates the original hypothesis as a question: "What is the relationship between reducing communication costs over time and the economics of different decision-making structures?" Rather than arguing for a choice between hierarchies and markets, now he argues in terms of centralized vs. decentralized decision makers. Importantly for our purposes he discusses the factors that will affect the choice between decision-making structures. Those three factors are: decision information, motivation, and trust.

Malone argues that decentralization is desirable when decision makers have access to information that cannot easily be centralized. Following the socialist calculation debate we label this as being the "Hayek condition." Decentralization is desirable when decision makers have the motivation to make decisions at the local level. Following the socialist calculation debate we label this as being the "Mises condition." Finally, decentralization is desirable when local decision makers do not trust central decision makers when making important decisions. This we can call the "Satoshi condition."

Unfortunately, Malone does not define what he means by the term "trust." He does provide some examples, "If I don't trust you, I don't want you to make decisions on my behalf." That does seem like a very intuitive notion, yet it is possible that a decision maker would prefer to make their own decisions even if they did "trust" another party. He suggests that information technology can enhance trust by increasing standardization, improving monitoring, and by better socializing remote decision makers. That position, however, simply begs the question, "What is trust?" Sundararajan (2016) bases his definition of trust on James Colemans' view that trust is "a willingness to commit to a collaborative effort before you know how the other person will behave." Werbach (2018) summarizes that definition into "confident vulnerability." Sundararajan argues that trust, in a digital environment, has five cues: prior interaction, learning of peer experience, branding, digitized social capital, and external validation. Importantly, he argues the latter two cues, digitized social capital and external validation, have not been available, at scale, until recently. Those networked platforms that are able to provide those cues at scale have become very large, very quickly.

Another way to approach the issue of trust is to do so within Oliver Williamson's framework. Economists tend to assume that rational individuals are self-interested. Williamson modifies that assumption to being individuals are opportunistic-individuals are self-interest seeking with guile. In the standard economic framework, individuals may be self-interested but they never lie, steal, or cheat. Williamson adds back bad behavior into the assumption of human behavior. One way to think of trust is as an absence of opportunism, or of constrained opportunism. This viewpoint would be consistent with Williamson's (1993a) suggestion that " $\mathrm{t}]$ rust is sometimes treated as an antonym for opportunism." Yet, Williamson (1993b) thinks this view is not quite correct and we agree. As Williamson argues, calculated cooperative behavior is not being trustworthy per se. Nonetheless treating an absence of opportunism or constrained opportunism as trust does provide some valuable insight into the operation of the electronic markets hypothesis.

Williamson operationalizes transaction costs by modifying the standard assumptions of economics. We have already discussed opportunism. He also relaxes the rationality assumption-from perfect rationality to bounded rationality. Bounded rationality is the recognition that there are limits to human cognition, and was proposed by the 1978 economics laureate Herbert Simon. Then Williamson relaxes the homogeneity assumption that economists routinely apply to capital. Rather than assuming that all capital is perfectly substitutable, Williamson introduces the notion of "asset specificity." This is the idea that capital can be deployed for a specific purpose and once deployed cannot then be redeployed without a substantial loss in value.

Bounded rationality, opportunism, and asset specificity shape the nature of choices available to decision makers when transacting with each other. Williamson describes four different types of "contracting process." The first can be described as a "short term" contract (Williamson calls this "competition"). Here, a buyer and seller interact for the sole purpose of undertaking a transaction in real time. Payment and delivery occur at the same time and there, in principle, no on-going relationship between the buyer and seller. Conversely, buyers and sellers may enter into long-term arrangements where payment and delivery are not synchronized. Here, the potential for "maladaptation" occurs - the contract as originally described and agreed to may not suit the parties to the contract over time. This could occur due to changing circumstances or opportunism on the part of the parties. There are three solutions to this possibility: comprehensive planning where every possibility is forecast and a contractual solution to every possibility is negotiated in advance; Promise is the insertion of a general clause into the contract to renegotiate in good faith and make each party whole after the fact; Governance constitutes 
TABLE 1 | Williamson's contracting processes.

\begin{tabular}{llll}
\hline $\begin{array}{l}\text { Asset } \\
\text { specificity }\end{array}$ & $\begin{array}{l}\text { Bounded } \\
\text { rationality }\end{array}$ & Opportunism & $\begin{array}{l}\text { Contracting } \\
\text { process }\end{array}$ \\
\hline Absent & $\sqrt{ }$ & $\sqrt{ }$ & Short term \\
$\sqrt{ }$ & Absent & $\sqrt{ }$ & Planning \\
$\sqrt{ }$ & $\sqrt{ }$ & Absent & Promise \\
$\sqrt{ }$ & $\sqrt{ }$ & $\sqrt{ }$ & Governance \\
& & & (hierarchies) \\
\hline
\end{tabular}

Source: Adapted from Williamson (1985), Berg et al. (2019).

substitution of hierarchy for market relationships-also known as vertical integration.

Table 1 illustrates the menu of alternatives faced by parties to a potential contract. Planning works in the absence of bounded rationality, and Promise works in the absence of opportunism. These situations, however, are rare. In Williamson's analysis, Governance manages bounded rationality and opportunism, while dealing with asset specificity.

Oliver Williamson has been able to provide more detail to Ronald Coase's original insight. We live within a world where transactions costs-including the cost of trust-drive the choice between operating within markets or within hierarchy. What if there were a technology that could, at least partially, constrain opportunism? The implications of a lack of opportunism are quite profound-Williamson (1993a) has argued then that "most forms of complex transacting and hierarchy [would] vanish." That precisely is the Electronic Market Hypothesis proposed by Malone, Yates, and Benjamin.

As Sundararajan has argued, it is only recently that networked platforms have been able to deliver digital trust at scale. There is, however, yet another technology that has the promise to industrialize trust. Blockchain technology is a distributed, digital, database, or ledger, with two critical properties: decentralization and immutability. Economic institutions provide a trust layer to govern complex exchange. Historically trust has been provided by market mechanisms such a reputation or hierarchythose organizations, such as firms and governments, that have suppressed opportunistic behavior through ranked authority. Blockchains industrialize this trust layer. Proof of work blockchains, such as Bitcoin, convert energy into economically valuable trust. Alternative consensus mechanisms convert economic coordination tools like voting or costly signaling (such as staking capital) into trust. Berg et al. $(2017,2019)$ describe this process in more detail.

Looking back at Table 1, Promise becomes a viable contracting process in the absence of opportunism-or in the world of greater trust. Those institutions-trusted third parties-that exist primarily for the purpose of providing trust to facilitate economic transactions face competition from the blockchain as an institutional technology (Davidson et al., 2018; Berg et al., 2019). This is an equivalent argument to the original Malone, Yates, and Benjamin hypothesis-yet provides a sounder rationale for the mechanism at work. The economic significance of this new source of industrialized trust cannot be understated. Arun Sundararajan (quoted in Daly, 2017) has argued: "If you look back at history, every time there was a big expansion in the world's economic activity, it was generally induced by the creation of a new form of trust."

\section{BLOCKCHAIN AS ECONOMIC INFRASTRUCTURE}

In precisely, the same way that the industrial revolution was driven by the provision of industrialized energy, at scale, so the digital revolution will be driven by the provision of industrialized trust, at scale. Chandler (1962) described the change in industrial organization following the industrial revolution as being a movement from the so-called $\mathrm{U}$-form organization to the $\mathrm{M}$ Form organization. With the industrialization of trust, we imagine the emergence of a "V-form" organization.

Where previously management had a choice between make or buy, they now face a choice as to whether to make, buy, or network. A V-form organization is an outsourced, vertically integrated organization tied together not by management and corporate hierarchy, but by a distributed ledger (i.e., a blockchain) (see Berg et al., 2018). The V-form organization would consist of a group of fully independent companies that effectively operate as one vertically integrated organization using blockchain technology to coordinate and audit what would have been previously done either through the corporate office, or in the market. Cooperation around a shared ledger provides many of the benefits of consolidation - trust-without the hierarchy costs of administrative bloat and inefficiency.

These V-form organizations would provide a trading infrastructure to a future digital economy. Right now economic infrastructure consists of physical infrastructure such as rail, roads, and ports and the like, as well as legal institutions and social norms that facilitate trade and economic activity. In a world of industrialized trust, it is easy to imagine an additional digital (blockchain) layer of economic infrastructure that both complements and substitutes for existing forms of economic infrastructure. While the digital layer of infrastructure would consist of hardware, software, and protocols it would largely constitute intangible infrastructure. An example of a $\mathrm{V}$-form organization would be the Aragon Network; virtual organizations can be created as a set of smart contracts and the network provides a dispute resolution mechanism. This can be described as being a decentralized organization entirely consistent with the electronic markets hypothesis. By contrast"centralized" V-form organizations can also be observed. The Tradelens platform developed by IBM and Maersk would be an example. Here, a V-form organizational structure has emerged from existing hierarchical organizations. Whether or not this manifestation of V-form organization is consistent with the electronic markets hypothesis is open for debate (see Centre for Blockchain Technologies, 2019 for a discussion of distributed ledger technology and supply chains).

The difficulties associated with intangible infrastructure are well-documented by Haskel and Westlake (2018). They describe intangible assets as having four unique properties: costs are sunk, intangible assets generate spillover effects, intangible 
assets are scalable, and intangible assets have synergies. These characteristics, in and of themselves, are not as unusual as Haskel and Westlake suggest-but nonetheless still pose something of a challenge in terms of infrastructure provision and financing.

Sunk costs and synergies are also associated with asset specificity. Scalability often suggests that the usage of an asset is non-rival. In the instance of networked platforms, the ability to capture (and possible share) spillovers is the business model that drives value creation. Scalability does pose some challenges. From an entrepreneurial perspective the ability to grow a business in response to market demand is important to driving profitability. From a public policy perspective it is important too. In the digital world, scalability suggests the importance of network effects. In the non-digital world, network effects are (often) associated with anti-competitive behavior that is then targeted by antitrust policy. It is an open question whether anti-trust policy as devised for a non-digital world characterized by physical scarcity is appropriate for a digital world.

In many countries, and historically, government has been a major infrastructure provider. Haskel and Westlake point to two problems with the notion of digital infrastructure. First, the pace of technological change is very fast in this space. Government investment may quickly become redundant. Second, infrastructure works well as a complement to existing private capital. The solution to both these problems is to let (even encourage) the private sector to provide digital infrastructure-i.e., build the V-form organizations. This solution involves two challenges. First the entrepreneurial challenge of devising profitable business models that will drive the private provision of public infrastructure. Second the public policy response to antitrust concerns, and privacy concerns, and the like that is beginning to characterize political engagement with the digital economy.

\section{REFERENCES}

Bastani, A. (2018). Fully Automated Luxury Communism: A Manifesto. Croydon: Verso Books.

Berg, C., Davidson, S., and Potts, J. (2017). "Blockchains industrialise trust," in SSRN Working Paper. Available online at: https:// papers.ssrn.com/sol3/papers.cfm?abstract_id $=3074070 \quad$ (accessed July 7, 2019).

Berg, C., Davidson, S., and Potts, J. (2018). "Outsourcing vertical integration: distributed ledgers and the V-form organisation," in SSRN Working Paper. Available online at: https://papers.ssrn.com/sol3/papers.cfm?abstract_ id=3300506

Berg, C., Davidson, S., and Potts, J. (2019). Understanding the Blockchain Economy: An Introduction to Institutional Cryptoeconomics. Cheltenham: Edward Elgar. doi: $10.4337 / 9781788975001$

Bleecker, S. E. (1994). The virtual organization. The Futurist 28, 2.

Byrne, J. (1993). The Virtual Corporation. Bloomberg. Available online at: https:// www.bloomberg.com/news/articles/1993-02-07/the-virtual-corporation (accessed July 6, 2019).

Carr, N. (2004). Does IT Matter? Information Technology and the Corrosion of Competitive Advantage. Boston, MA: HBS Press. doi: 10.1145/1022348.10 22349

\section{CONCLUSION}

Carr (2004) is somewhat underwhelmed by the information technology revolution, asking the question "does IT matter?" It is apparent from his treatment of the material that information technology did not seem to matter very much. Malone (and his co-authors) had been arguing since the late 1980s that information technology was going to dramatically restructure industrial organization. Yet that had not happened. Communication costs had fallen, but we argue that only electronic communication effect had operated until the early twenty first century. Viable business models began appearing in the late twentieth and early twenty first century. The big digital platforms that we now observe in the economy-Facebook, Google, Amazon-were founded in that era. This is the electronic brokerage effect at work. What we have yet to see operate at scale is the electronic integration effect. That, we believe, is because an important ingredient of the electronic markets hypothesis has been missing. The electronic markets hypothesis is not driven by a reduction in communication costs per se, but rather by a reduction in the cost of trust. We can conclude that blockchain technology offers an infrastructure for electronic integration, and the realization of the electronic markets hypothesis.

\section{AUTHOR CONTRIBUTIONS}

This paper was jointly conceptualized and written by $\mathrm{CB}, \mathrm{SD}$, and JP.

\section{FUNDING}

We thank Liming Zhu, Mark Staples, and Rob Hanson from Data61, a research division within the Australian Government's CSIRO, for discussion and feedback of the core ideas in this paper, as well as for (partial) research support.

Centre for Blockchain Technologies. (2019). Distributed Ledger Technology in the Supply Chain. Available online at: http://blockchain.cs.ucl.ac.uk/wp-content/ uploads/2019/08/DLT-in-the-Supply-Chain_UCL-CBT.pdf

Chace, C. (2016). The Economic Singularity: Artificial Intelligence and the Death of Capitalism. Bradford: Three Cs.

Chandler, A. (1962). Strategy and Structure: Chapters in the History of the American Industrial Enterprise. Boston, MA: The MIT Press.

Coase, R. (1937). The nature of the firm. Economica 4, 386-405. doi: 10.1111/j.1468-0335.1937.tb00002.x

Crossman, A., and Lee-Kelley, L. (2004). Trust, commitment and team working: the paradox of virtual organizations. Global Netw. 4, 375-390. doi: 10.1111/j.1471-0374.2004.00099.x

Daly, J. (2017). Trust becomes the fuel that powers a new economy. Medium. Available online at: https://medium.reinvent.net/the-power- of-trusta792f768e 8 b8

Daugherty, P. R., and Wilson, H. J. (2018). Human + Machine: Reimagining Work in the Age of AI. Boston, MA: Harvard Business Review Press.

Davidson, S., De Filippi, P., and Potts, J. (2018). Blockchains and the economic institutions of capitalism. J. Inst. Econ. 14, 639-658. doi: 10.1017/S1744137417000200

Handy, C. (1995). Trust and the virtual organization. Harvard Business Review, 40-50. 
Harris, M. (2002). "Rethinking the virtual organisation," in Teleworking: International Perspectives: From Telecommuting to the Virtual Organisation, eds P. J. Jackson and J. M. Van Der Wielen (Routledge), 94-112.

Haskel, J., and Westlake, S. (2018). Capitalism Without Capital: The Rise of the Intangible Economy. Princeton, NJ: Princeton University Press. doi: $10.1515 / 9781400888320$

Hayek, F. (1945). The use of knowledge in society. Am. Econ. Rev. 35, 519-530.

Hughes, J. A., O’Brien, J., Randall, D., Rouncefield, M., and Tolmie, P. (2001). Some 'real' problems of 'virtual' organisation. New Technol. Work Employ. 16, 49-64. doi: 10.1111/1468-005X.00076

Jones, T. M., and Bowie, N. E. (1998). Moral hazards on the road to the "virtual" corporation. Bus. Ethics Q. 8, 273-292. doi: 10.2307/3857329

Kasper-Fuehrera, E. C., and Ashkanasy, N. M. (2001). Communicating trustworthiness and building trust in interorganizational virtual organizations. J. Manag. 27, 235-254. doi: 10.1177/014920630102700302

Lavoie, D. (1985a). [2015]. Rivalry and Central Planning. Arlington, TX: Mercatus Centre.

Lavoie, D. (1985b). [2016]. National Economic Planning: What Is Left? Arlington, TX: Mercatus Centre.

Malone, T. (1987). Modeling coordination in organizations and markets. Manag. Sci. 33, 1317-1332. doi: 10.1287/mnsc.33.10.1317

Malone, T. (2003). "Is empowerment just a fad? Control, decision making, and IT," in Inventing the Organizations of the $21^{\text {st }}$ Century, eds T. Malone, R. Laubacher, and M. Scott Morton (The MIT Press), p. 49-69.

Malone, T., and Rockart, J. (1991). Computers, networks and the corporation. Sci. Am. 265, 128-136. doi: 10.1038/scientificamerican0991-128

Malone, T., Yates, J., and Benjamin, R. (1987). Electronic markets and electronic hierarchies. Commun. ACM 30, 484-497. doi: 10.1145/214762. 214766

Malone, T. W., Yates, J., and Benjamin, R. I. (1989). The logic of electronic markets. Harvard Business Review, 166-169.

Mason, P. (2015). PostCapitalism: A Guide to Our Future. London: Allen Lane.

Miles, R. E., and Snow, C. C. (1984). Fit, failure and the hall of fame. California Management Review 26:3. doi: 10.2307/41165078

Miles, R. E., and Snow, C. C. (1986). New concepts for new forms. California management review 28:3. doi: 10.2307/41165202
Morris, K. (2019). Fear the economic singularity: will machines own us? Electronic Engineering Journal. Available online at: https://www.eejournal.com/article/ fear-the-economic-singularity/

Rasmussen, L. B., and Wangel, A. (2007). Work in the virtual enterprisecreating identities, building trust, and sharing knowledge. AI Soc. 21:184. doi: 10.1007/s00146-005-0029-y

Riemer, K., and Klein, S. (2008). Is the V-form the next generation organisation? An analysis of challenges, pitfalls and remedies of ICT-enabled virtual organisations based on social capital theory. J. Inform. Technol. 23, 147-162. doi: 10.1057/palgrave.jit.2000120

Shockley-Zalabak, P., Ellis, K., and Winograd, G. (2001). Organizational trust: what it means, why it matters. Org. Dev. J. 18, 35-48.

Sundararajan, A. (2016). The Sharing Economy: The End of Employment and the Rise of Crowd-Based Capitalism. Cambridge, MA: The MIT Press.

Werbach, K. (2018). The Blockchain and the New Architecture of Trust. Cambridge, MA: The MIT Press. doi: 10.7551/mitpress/11449.001.0001

Wigand, R. T. (2011). 20 years of research in electronic markets and networked business: an interview with Thomas Malone. Electron. Mark. 21, 5-17. doi: 10.1007/s12525-011-0053-3

Williamson, O. (1985). The Economic Institutions of Capitalism. New York, NY: Free Press.

Williamson, O. (1993a). Opportunism and its critics. Manag. Dec. Econ. 14, 97-107. doi: 10.1002/mde.4090140203

Williamson, O. (1993b). Calculativeness, trust, and economic organization. J. Law Econ. 36, 453-486. doi: 10.1086/467284

Conflict of Interest: The authors declare that the research was conducted in the absence of any commercial or financial relationships that could be construed as a potential conflict of interest.

Copyright (C) 2019 Berg, Davidson and Potts. This is an open-access article distributed under the terms of the Creative Commons Attribution License (CC BY). The use, distribution or reproduction in other forums is permitted, provided the original author(s) and the copyright owner(s) are credited and that the original publication in this journal is cited, in accordance with accepted academic practice. No use, distribution or reproduction is permitted which does not comply with these terms. 